\title{
The Order of the Factors Affects a Product!
}

Patients receiving nebulized respiratory treatments and airway clearance therapies often combine the treatments to decrease treatment time, despite a lack of data supporting this practice. Moreover, manufacturers advertise simultaneous use in their marketing. The airway clearance devices that allow concomitant administration of aerosol can be classified as those that alter the pathway of the aerosol and those that do not.

We all learn in algebra that the order of the factors does not affect a product. However, this might not be true in respiratory care practice. In this issue of RESPIRATORY CARE, Mesquita et $\mathrm{al}^{1}$ report the findings of an in vivo study of the effect of different configurations of a high-frequency

\section{See the Original Study on Page 328}

oscillatory positive expiratory pressure (PEP) device (Acapella) and a jet nebulizer on pulmonary deposition of a radio-labeled aerosol in normal subjects. The Acapella alters the pathway of the aerosol. Mesquita et al found no difference in lung deposition between the nebulizer alone and the nebulizer interposed between the mouthpiece and the Acapella. However, when the nebulizer was connected to the back of the Acapella, as recommended by the manufacturer, there was a $70 \%$ decrease in pulmonary deposition. There was a non-significant trend toward more peripheral distribution of the aerosol. Mesquita et al also measured the effect of the nebulizer position on the pattern of aerosol deposition within the Acapella.

One limitation of the study is that it was done in healthy subjects. Based on previously published data, one would expect that deposition would be greater in subjects with lung disease. ${ }^{2}$ Moreover, aerosol distribution varies significantly with disease severity. ${ }^{3}$ However, because the reduction in emitted aerosol occurs before inhalation, we would expect similar results in subjects with lung disease.

Dr Berlinski has disclosed relationships with Johnson \& Johnson, MPEX Pharmaceutical, Gilead, Philips, Genentech, Vertex, Abbvie, Aptalis, Janssen Teva, Therapeutic Development Network, and S\&T Technologies.

Correspondence: Ariel Berlinski MD, Department of Pediatrics, University of Arkansas for Medical Sciences, 1 Children's Way, Slot 512-17, Little Rock AR 72202. E-mail: BerlinskiAriel@uams.edu.

DOI: $10.4187 /$ respcare. 03088
Drug and device developers, manufacturers, researchers, and regulatory agencies struggle to find good in vivo/ in vitro correlation to aid development and approval processes of new drugs and devices. Our group recently reported the effect of concomitant use of nebulizer and PEP devices on drug output and aerosol characteristics. ${ }^{4}$ We found that coupling the nebulizer with a PEP device that obstructs the aerosol pathway reduces the aerosol particle size and patient dose. The former finding was measured via cooled cascade impactor technique, and the latter finding was measured via breathing simulation technique. The mass median aerodynamic diameter decreased $70 \%$, from $4.13 \mu \mathrm{m}$ with the nebulizer alone (equivalent to configuration $\mathrm{C}$ of Mesquita's report) to $1.24 \mu \mathrm{m}$ when coupled to the Acapella Choice (equivalent to configuration A of Mesquita's report). In addition, the amount of drug captured in the cascade impactor decreased by $65 \%$ when the nebulizer was coupled to the Acapella Choice. The device retained $75 \%$ of the drug that left the nebulizer. The patient dose also decreased $80-90 \%$ when the nebulizer was coupled to the Acapella Choice. Good correlation was found between the previously published in vitro data and the in vivo data reported by Mesquita et al ${ }^{1,4}$

The drug loss that occurs when the nebulizer is placed after the Acapella has both financial and clinical consequences. Dornase alfa and inhaled antibiotics are used by patients with cystic fibrosis, who also use PEP devices for airway clearance..$^{5,6}$ If used together, the patients will be under-dosed and expensive medications will be wasted.

Healthcare practitioners need to carefully evaluate the evidence available regarding the efficiency of different devices before considering their use. This is even more relevant when 2 therapies are combined, because in respiratory care the order of the factors affect a product.

Ariel Berlinski MD

Pediatric Aerosol Research Laboratory Arkansas Children's Hospital Research Institute and Pulmonology Section Department of Pediatrics University of Arkansas for Medical Sciences Little Rock, Arkansas

\section{REFERENCES}

1. Mesquita FO, Galindo-Filho VC, Neto JL, Galvão AM, Fink JB, Dornelas-de-Andrade A. Scintigraphic assessment of radio-aerosol pul- 


\section{The Order of the Factors Affects a Product!}

monary deposition with the Acapella positive expiratory pressure device and various nebulizer configurations. Respir Care 2014;59(3):328-333.

2. Kim CS, Kang TC. Comparative measurement of lung deposition of inhaled fine particles in normal subjects and patients with obstructive airway disease. Am J Respir Crit Care 1997;155(3):899-905.

3. Diot P, Palmer LB, Smaldone A, DeCelie-Germana J, Grimson R, Smaldone GC. RhDNase I aerosol deposition and related factors in cystic fibrosis. Am J Respir Crit Care Med 1997;156(5):1662-1668.

4. Berlinski A. In-vitro evaluation of positive expiratory pressure devices attached to nebulizers. Respir Care 2014;59(2):216-222.
5. Mogayzel PJ Jr, Naureckas ET, Robinson KA, Mueller G, Hadjiliadis D, Hoag JB, et al; Pulmonary Clinical Practice Guidelines Committee. Cystic fibrosis pulmonary guidelines. Chronic medications for maintenance of lung health. Am J Respir Crit Care Med 2013; 187(7):680-689.

6. Flume PA, Robinson KA, O'Sullivan BP, Finder JD, Vender RL, Willey-Courand DB, et al; Clinical Practice Guidelines for Pulmonary Therapies Committee. Cystic fibrosis pulmonary guidelines: airway clearance therapies. Respir Care 2009;54(4):522537. 